\title{
Conhecimento de moradores sobre frugivoria por aves em uma região urbanizada e com fragmentos de restinga no sudeste do Brasil
}

\author{
César Cestari \\ PPG em Zoologia, UNESP, Rio Claro - SP, Brasil \\ Endereço para correspondência \\ Maria das Dores Rodrigues, 569, CEP 11740-000, Itanhaém - SP, Brasil \\ cesar_cestari@yahoo.com.br
}

Submetido 23/10/2008

Aceito para publicação 06/03/2009

\section{Resumo}

O conhecimento ecológico é importante para revelar a consciência ambiental de pessoas, refletindo em ações para conservação no meio ambiente onde vivem. No presente estudo foi avaliado o conhecimento de moradores sobre frugivoria por aves em fragmentos da restinga, um ecossistema ameaçado pela crescente ocupação humana. Entrevistas semi-estruturadas foram aplicadas para 73 moradores em dois bairros da cidade de Itanhaém, litoral sul do estado de São Paulo. A maioria das respostas evidenciou pouca observação de frugivoria por aves em plantas nativas. Os moradores demonstraram dificuldades na identificação de aves frugívoras e na discriminação de plantas nativas da região. No entanto, possuíam conhecimento lógico de processos ecológicos envolvendo as interações entre aves e plantas. A ave popularmente conhecida como tiê-sangue (Ramphocelus bresilius) e a palmeira jerivá (Syagrus romanzoffiana) foram mais frequentemente citadas. Essas espécies são facilmente encontradas na restinga da região e apresentam características estruturais que atraíram a atenção das pessoas tais como cor vermelho intenso e elevada altura, respectivamente. Dessa forma, as epécies citadas podem ser utilizadas para trabalhos iniciais envolvendo identificação de aves e plantas, e para o aprofundamento da educação ambiental dos moradores locais.

Unitermos: dispersão, etnologia, frutos, Ramphocelus bresilius

\section{Abstract}

Knowledge of dwellers about frugivory by birds in an urbanized region with restinga fragments in southeastern Brazil. Ecological knowledge can be important to reveal in raising the awareness of people which becomes reflected in action on their local environment. This study evaluated the knowledge of dwellers about frugivory by birds in restinga fragments, an ecosystem threatened due to the rapid increase of human demographic expansion. A semi-structured interview was applied to 73 dwellers from two districts of Itanhaém on the south coast of São Paulo state. The majority of answers indicated little observation of bird frugivory in native plants. Dwellers found it difficult to identify birds and to discriminate native plants in nature. However, they had some logical knowledge of the ecological processes involved in bird-plant interactions. The Brazilian Tanager (Ramphocelus bresilius) and Jerivá Palm (Syagrus romanzoffiana) were the most cited species. These species are most easily found in the restinga and present some characteristics that attract the attention of people, such as: intense red color and great height, respectively. These species may be used as initial steps for works 
involving the identification of birds and plants in the ecosystem as well as for a deepening of environmental education by the local population.

Key words: dispersion, ethnology, fruits, Ramphocelus bresilius

\section{Introdução}

A relação mutualística proveniente da interação entre aves frugívoras e plantas é fundamental para manutenção destas comunidades animais e vegetais e, por consequência, na conservação de áreas nativas que ainda restam em locais urbanizados (Oliveira, 1987, 1999). A produção de frutos atrai populações de aves, que por sua vez, exercem ação efetiva na dispersão de sementes e recrutamento de plantas (Howe, 1981; Terborgh, 1986; Pizo, 1997). Em uma análise global, Staggemeier e Galetti (2007) apontaram que áreas altamente antropizadas decorrente de ações como a urbanização e degradação ambiental são menos visitadas por aves frugívoras, podendo comprometer o crescimento populacional de plantas.

Apesar de pouco protegida de ameaças provindas da crescente ocupação humana, a planície com fragmentos remanescentes de restinga na região sudeste do Brasil é considerada uma importante área na conservação de aves e biodiversidade, abrigando espécies ameaçadas e endêmicas (Sampaio, 2005; Bencke et al., 2006). Muitos vestígios do homem pré-histórico evidenciam a antiga exploração desse ecossistema, no entanto, foi a partir do século XV que a região costeira do Brasil começou a ser explorada intensamente pelos colonizadores europeus, levando a uma crescente ocupação do litoral e aumento do impacto antrópico em áreas de restinga (Sampaio, 2005).

Estudos etnocientíficos envolvendo a importância ecológica de frugivoria por aves ainda são escassos no Brasil (Farias e Alves, 2007) e, podem refletir o grau de consciência ecológica das pessoas para a preservação do meio ambiente. A atração e curiosidade humana pelas formas, colorações das aves e plantas nativas também podem ser úteis para formulação de projetos de conservação e educação ambiental (Oliveira, 1987; Cestari, 2006).

Desta forma, no presente trabalho, foi avaliado o conhecimento de moradores sobre a importância da interação entre aves frugívoras e plantas nativas em uma região urbanizada com remanescentes de vegetação de restinga em Itanhaém, litoral sul do estado de São Paulo.

\section{Material e Métodos}

\section{Área de estudo}

O estudo foi realizado nos bairros Jardim Jamaica e Bopiranga na região sudoeste da zona urbana do município de Itanhaém (2413'39, 7’'S; 4652'19,8”O; Figura 1). A área de estudo possui estimativa populacional de 2.600 pessoas residentes e caracteriza-se por um mosaico de fragmentos de vegetação nativa de restinga, casas e estabelecimentos comerciais (Prefeitura Municipal de Itanhaém, 2005). Os moradores das casas intercaladas a esses fragmentos são permanentes ou temporários, sendo que os últimos frequentam a região somente em finais de semana e períodos de férias.

A complexidade da vegetação dos fragmentos de restinga da região segue o padrão normal encontrado neste tipo de ecossistema, aumentando da praia em direção ao interior da planície costeira (Sampaio, 2005). Alguns típicos representantes arbóreos são: Ocotea sp., (Lauraceae), Syagrus romanzoffiana (Arecaceae), Eugenia sp., Psidium sp. (Myrtaceae) e Rapanea sp. (Myrsinaceae) (Bencke et al., 2006). A avifauna é composta de aproximadamente 225 espécies (D. Buzzetti, dados não publicados), sendo que uma espécie endêmica e ameaçada (papagaio-de-cara-roxa, Amazona brasiliensis) é encontrada periodicamente sobrevoando a área de estudo (observação pessoal).

\section{Metodologia}

A coleta de dados foi realizada nos dias 18 a 21, 24, 27 e 28 de março de 2008 com o emprego de entrevista semi-estruturada aos moradores. Neste tipo de entrevista, foi utilizado um roteiro com três questões básicas, permitindo que os entrevistados respondessem de maneira Ad libitum, sem a interferência do entrevistador em suas respostas (Tabela 1). As casas de moradores intercaladas às áreas de vegetação nativa foram selecionadas aleatoriamente para a aplicação 


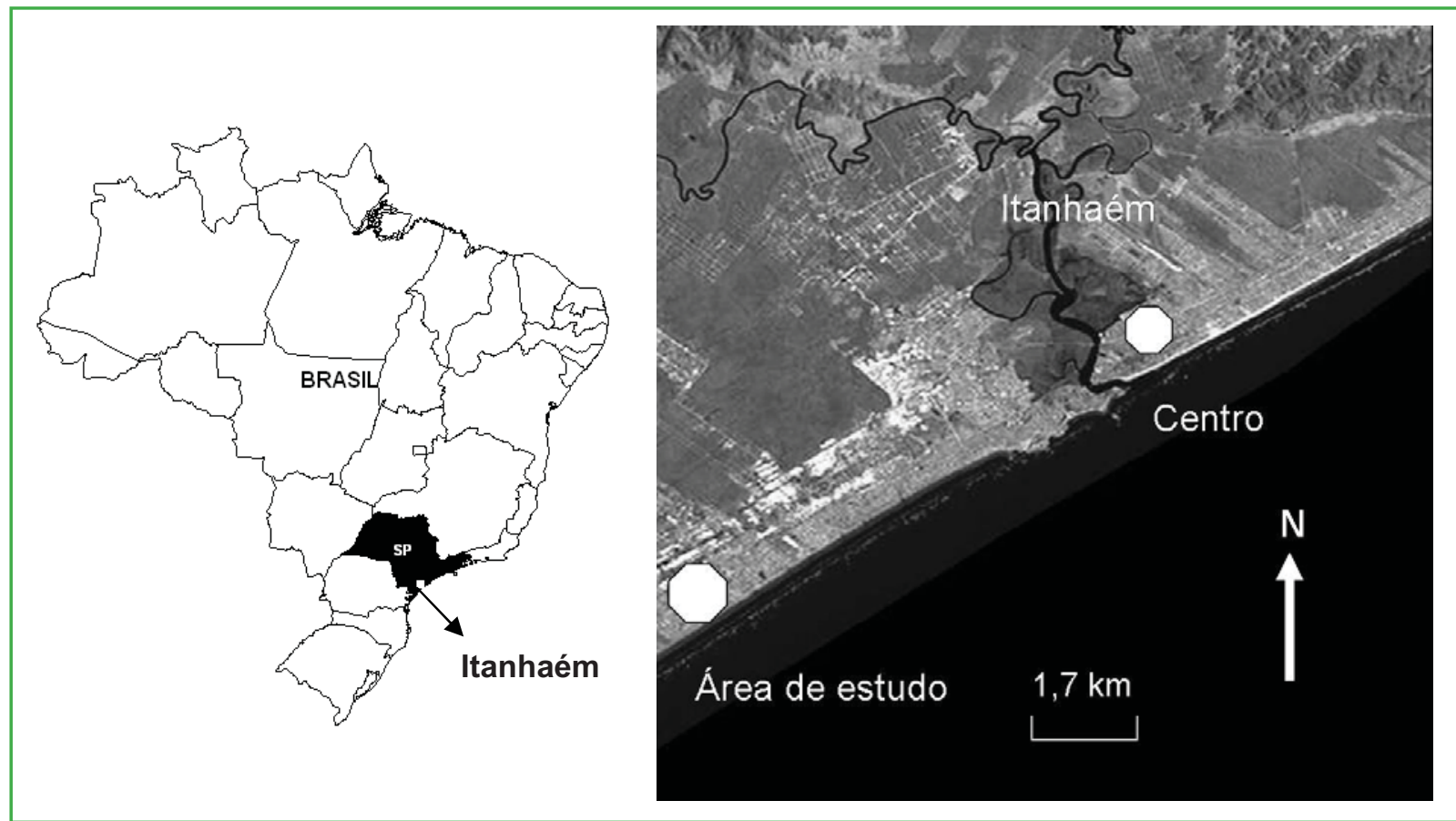

FIGURA 1: Área de estudo localizada ao sudoeste do centro urbano do município de Itanhaém, estado de São Paulo (modificado de Google Earth 2008).

da entrevista em situação. Neste procedimento, o morador respondeu às questões ao mesmo tempo em que observou a paisagem com vegetação. Quando não havia paisagem nativa aos arredores do domicílio, o entrevistador realizou comentários sobre as estruturas e formas de paisagens nativas de restinga antes do início da entrevista, dando exemplos de locais próximos às casas dos entrevistados.

TABELA 1: Roteiro de entrevista para moradores dos bairros Bopiranga e Jardim Jamaica, Itanhaém, estado de São Paulo.

\begin{tabular}{|c|c|c|}
\hline \multicolumn{3}{|l|}{ Nome: } \\
\hline \multicolumn{3}{|l|}{ Endereço: } \\
\hline \multicolumn{3}{|l|}{ Idade: } \\
\hline Tempo de residência & ( ) temporário & ( ) permanente \\
\hline \multicolumn{3}{|c|}{ Local de origem (anterior à atual moradia): } \\
\hline \multicolumn{3}{|c|}{$\begin{array}{l}\text { Pergunta 1: Você já viu alguma ave se alimentando de fru- } \\
\text { tos em plantas nos terrenos nativos próximos à sua casa? }\end{array}$} \\
\hline \multicolumn{3}{|c|}{$\begin{array}{l}\text { Pergunta 2: Quais aves em quais plantas? (descrição mor- } \\
\text { fológica, nomes populares ou científicos). }\end{array}$} \\
\hline \multicolumn{3}{|c|}{ Pergunta 3: Qual a importância deste tipo de interação? } \\
\hline
\end{tabular}

O conhecimento dos moradores foi avaliado qualitativamente, agrupando-se as respostas em categorias com conteúdos de informação semelhantes. Os nomes comuns de aves e suas respectivas dietas citadas pelos moradores foram comparados com listas de aves e observações sobre o comportamento de alimentação das aves na região (Cestari, 2006; C. Cestari, dados não publicados) e literatura (Sick 1997). Os nomes de plantas citados foram comparados com listas de plantas nativas de restinga existentes para as regiões mais próximas ao local de estudo (Souza e Capellari Jr., 2004; Sampaio, 2005).

\section{Análise dos dados}

Foi utilizado o teste do Qui-Quadrado $\left(\chi^{2}\right)$ para verificar diferenças no número de citações das seguintes variáveis pelos moradores: (1) observação e não observação de interação entre aves e plantas em áreas nativas e (2) categoria de resposta sobre informações ecológicas e outras categorias de informações. A hipótese nula correspondeu a não existência de diferenças entre essas variáveis binárias. O nível de significância de $\alpha=5 \%$ foi estabelecido para este tipo de análise. 


\section{Resultados}

Características dos entrevistados - Foram entrevistados 73 moradores, dos quais 52 residiam permanentemente, 20 residiam temporariamente e um morador que não revelou este tipo de informação. A maioria das pessoas $(74 \%, \mathrm{n}=54)$ eram originárias ou residiam anteriormente na região da "grande São Paulo", que abrange o município de São Paulo e municípios vizinhos (Santo André, São Bernardo do Campo, Santo André e Osasco). A média de idade dos moradores foi de 50,6 $\pm 16,3$ anos e a média do tempo em que residiam nos bairros foi de 12,6 \pm 11 anos.

Observação de interação e identificação de aves e plantas - As respostas dos entrevistados incluíram: (1) as observações de interação entre aves frugívoras e plantas em áreas nativas, (2) as observações de interação entre aves frugívoras e plantas nos quintais das casas e (3) as observações de interação entre aves e frutos disponibilizados pelos moradores nos quintais das casas. A maioria das respostas (74\%) referiram-se à não observação de interação entre aves frugívoras e plantas nativas em fragmentos de restinga $\left(\chi_{(1)}^{2}=19,8\right.$; $\mathrm{P}<<0,001, \mathrm{n}=85)$.
Treze (59\%) dos 22 nomes populares de aves foram corretamente citados por possuírem pelo menos parte da dieta frugívora, sendo o tiê-sangue (Ramphocelus bresilius) observado frequentemente (Figura 2).

De acordo com os entrevistados que afirmaram terem observado interação entre aves frugívoras e plantas somente em áreas nativas, seis (46\%) das 13 plantas frutíferas foram corretamente citadas como nativas, sendo a palmeira-jerivá (Syagrus romanzoffiana) e o ingá (Inga sp.) observadas frequentemente (Figura 3).

Importância da interação entre aves frugivoras e plantas - foram agrupadas 12 categorias de respostas diferentes. As categorias sobre informações ecológicas foram comparativamente superiores e possuíam maior quantidade de citações (83\%) se comparadas à de outras categorias de respostas $\left(\chi_{(1)}^{2}=41,8 ; \mathrm{P}<<0,001, \mathrm{n}=\right.$ 104). As informações ecológicas mais frequentemente citadas foram que este tipo de interação é importante para a alimentação e sobrevivência das aves e, para a dispersão de sementes das plantas nas quais as aves se alimentam (Figura 4).

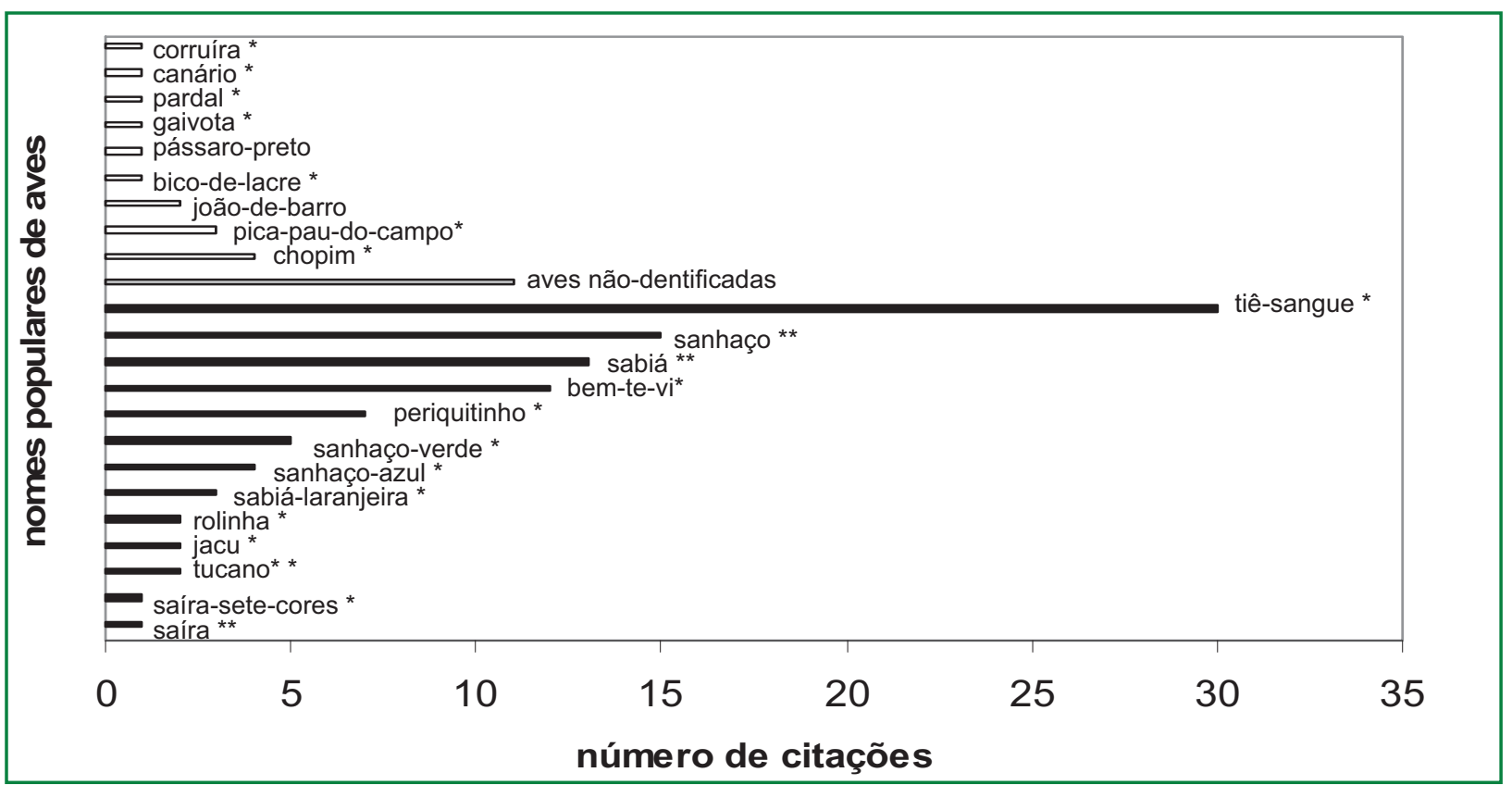

FIGURA 2: Número de citações de nomes populares das aves por moradores. As colunas preenchidas em preto representam aves com pelo menos parte da dieta frugívora na região. As colunas preenchidas em branco representam aves que não possuem dieta frugívora. *nomes populares representativos de espécies científicas, por exemplo o sanhaço-verde $=$ Thraupis palmarum; **nomes populares representativos de gêneros científicos, por exemplo o sanhaço $=$ Thraupis sp. 


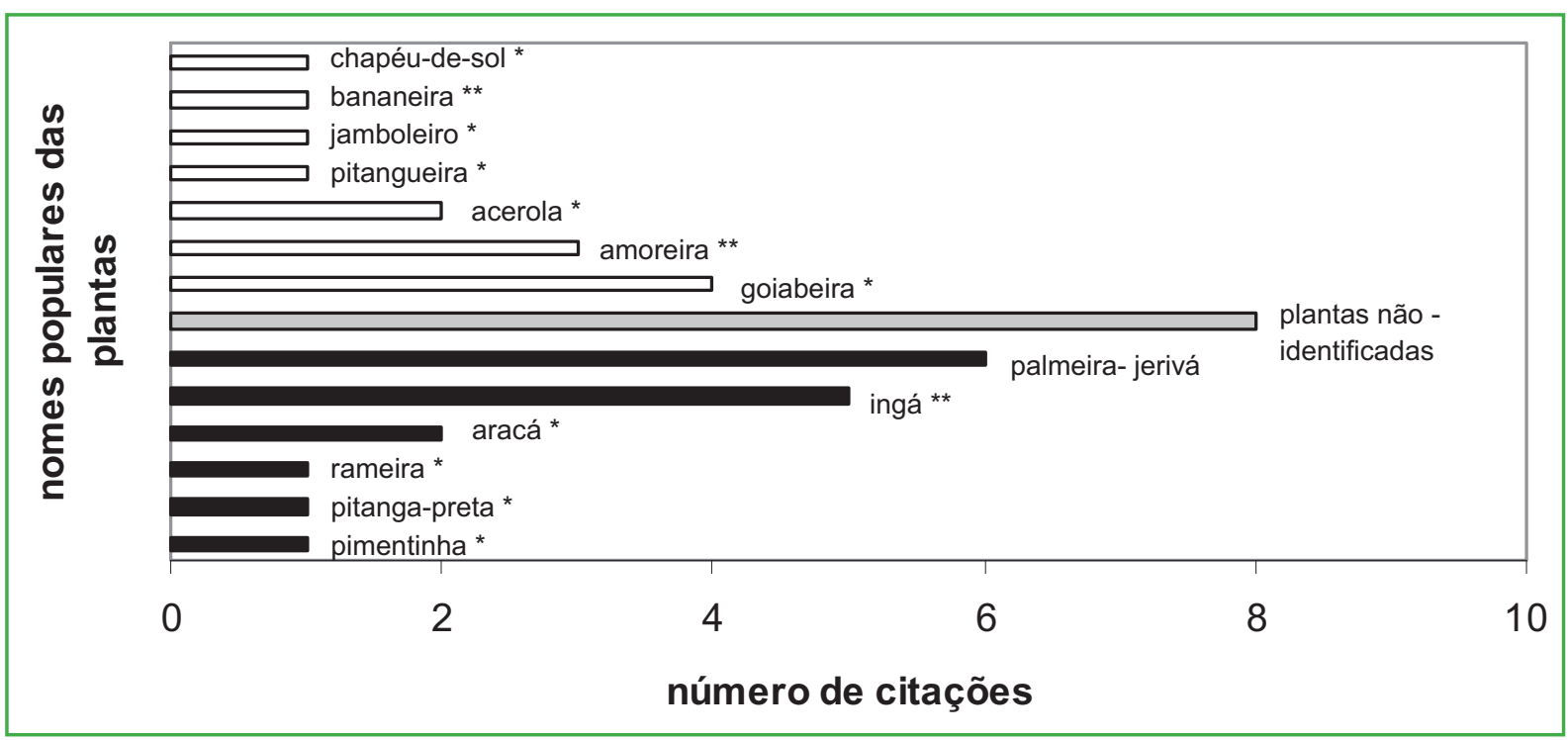

FIGURA 3: Número de citações de nomes populares das plantas por moradores. As colunas preenchidas em preto representam plantas nativas na região. As colunas preenchidas em branco representam plantas não nativas. *nomes populares representativos de espécies científicas, por exemplo o araçá = Psidium cattleyanum; **nomes populares representativos de gêneros científicos por exemplo o ingá $=$ Inga sp.

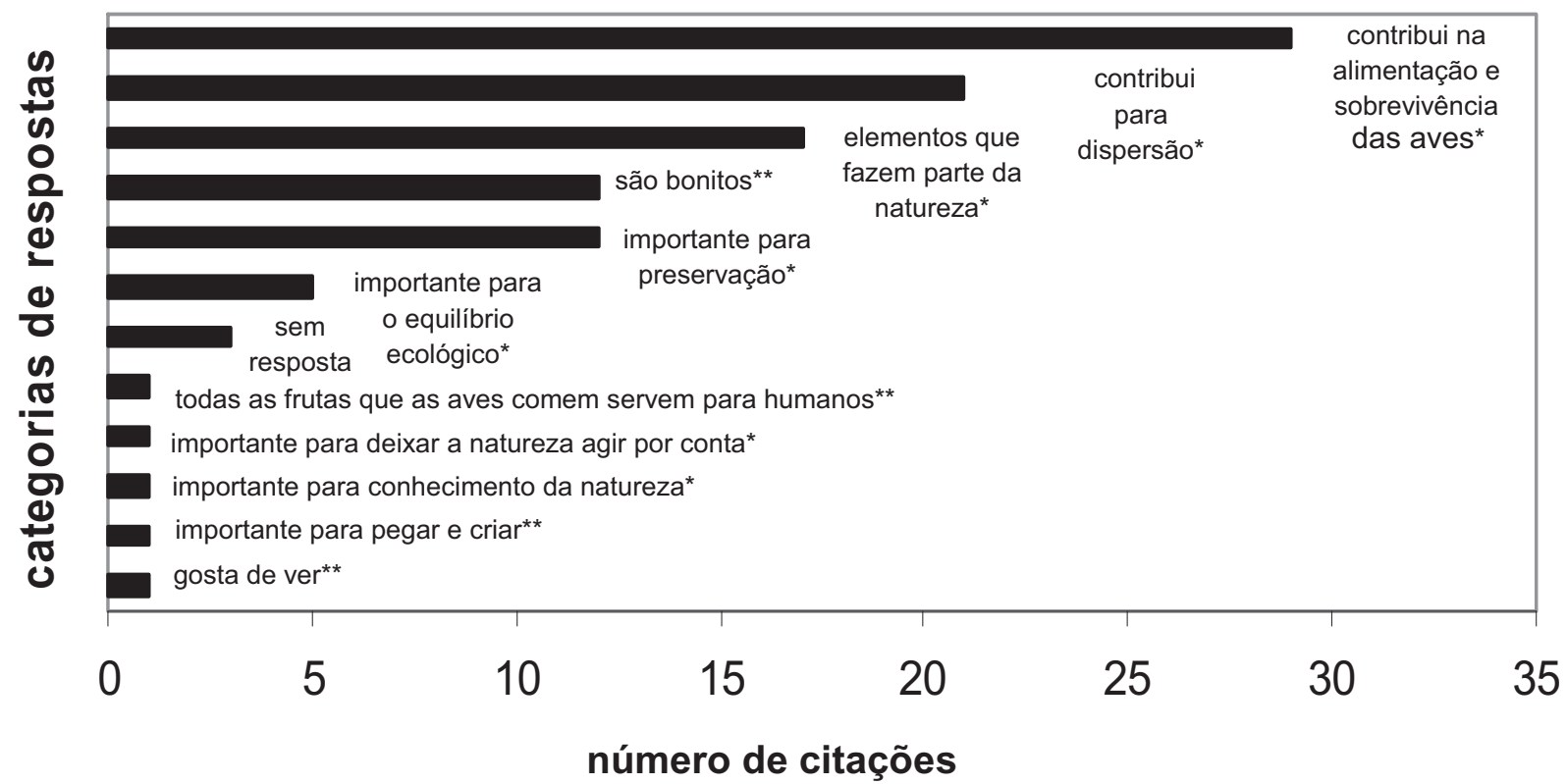

FIGURA 4: Número de citações das categorias de respostas dos moradores sobre a importância da interação entre aves frugívoras e plantas nativas. *categoria com informações ecológicas; **categorias com outras informações.

\section{Discussão}

A população amostrada pouco observou a interação de aves com plantas nos fragmentos de restinga. Quando a observação de interação existiu, a deficiência das pessoas para identificar aves e no conhecimento sobre o local de origem das plantas citadas também foi notável.
A maioria das pessoas entrevistadas justificaram a falta de observação por frequentarem principalmente a praia no período de lazer, não focando a atenção em "terrenos" de restinga. Muitas delas desconheciam que as áreas apontadas durante a entrevista eram nativas e estão em crescente ameaça devido ao avanço do processo de urbanização. $\mathrm{O}$ fato da maioria das pessoas 
entrevistadas terem sido originárias ou residirem a maior parte do tempo de suas vidas em uma região intensamente urbanizada, como a "grande São Paulo", pode ter influenciado na aparente falta de conhecimento da paisagem nativa e dos seres vivos que a compõem.

Algumas aves foram erroneamente citadas como frugívoras e possuem dietas predominantemente insetívora (chopim, pica-pau-do-campo, joão-de-barro, pássaro-preto e corruíra), granívora (bico-de-lacre, canário), onívora (pardal) e piscívora (gaivota) na região. Considerando as aves com pelo menos parte da dieta frugívora, o tiê-sangue (R. bresilius) foi o mais citado e prontamente lembrado pelos moradores no período da entrevista. Provavelmente, este resultado esteja fortemente relacionado com a elevada abundância da espécie na região e a plumagem com coloração vermelho intensa do macho adulto, atraindo a atenção das pessoas. De acordo com Castiglioni et al. (1995), o tiê-sangue possui importância para dispersão e aumento da velocidade de germinação de plantas de restinga. A coloração "chamativa" desta espécie associada ao seu papel ecológico e à sua vulnerabilidade ao desaparecimento do ecossistema por ações antrópicas destrutivas à restinga (Naka et al., 2002), podem ser características facilmente utilizadas na efetividade do processo de educação ambiental de moradores da região (Cestari, 2006).

Apesar de algumas espécies de plantas terem sido introduzidas em fragmentos de restinga (goiabeira Psidium guajava, amoreira Morus sp., acerola Malpighia emarginata e bananeira Musa sp., são as mais frequentemente observadas), a maioria das plantas frutíferas citadas pelos moradores não são nativas e foram classificadas erroneamente como tais. É possível que este erro de classificação das plantas esteja relacionado por serem "facilmente encontradas nos terrenos", criando uma falsa impressão dos moradores quanto a sua natividade. Da mesma maneira, a elevada abundância e altura destacável (10 a $12 \mathrm{~m})$ da palmeira-jerivá (Syagrus romanzoffiana) provavelmente influenciou a maior quantidade de respostas citando-a corretamente como uma espécie nativa na restinga da região (Souza e Capellari Jr., 2004; Sampaio, 2005).

Grande parte das respostas referentes especificamente à importância da interação entre aves e plantas seguiram uma lógica conceitual ecológica correta, sendo atribuídas à sobrevivência de aves e plantas e à consequente preservação do ambiente em que vivem principalmente pela ação de dispersão de sementes pelas aves (Howe, 1981). Além disso, os moradores citaram que as aves e plantas são elementos integrantes da paisagem e que contribuem para aumentar a beleza cênica da região. Esses resultados reforçam a idéia de implementação de uma política de fortalecimento turístico associado à conservação e valorização ambiental dos fragmentos de restinga que estão em crescente declínio na região sudeste e outras regiões da costa do Brasil, devido principalmente à expansão urbana no litoral decorrente da construção de loteamentos, ampliação de áreas de agricultura para subsistência e proximidade aos grandes centros urbanos (Sampaio, 2005; Bencke et al., 2006).

Os dados deste estudo indicaram que a maioria dos entrevistados tem conhecimento da importância ecológica das aves e plantas para o meio ambiente, no entanto é perceptível que esses conhecimentos são pouco originários da observação do meio ambiente nativo local. As espécies de aves e plantas mais citadas possuíam características estruturais que atraem a atenção dos moradores (tiê-sangue e palmeira jerivá). Desta forma, é recomendável que as espécies mais chamativas à população devam ser utilizadas em trabalhos de identificação de aves e plantas da restinga como ferramenta inicial para despertar o interesse em questões ecológicas mais complexas e fundamentais para a conservação deste ecossistema.

\section{Agradecimentos}

Meus sinceros agradecimentos aos moradores de concederam as entrevistas, ao Paulo Ricardo Gimenes por me ajudar na logística para realização das entrevistas e à professora Maria Christina de Mello Amorozo pelos comentários e sugestões desde o início da elaboração desse estudo.

\section{Referências}

Bencke, G. A.; Maurício, G. N; Develey, P. F.; Goerck, J. M. 2006. Áreas importantes para conservação das aves no Brasil. Parte 1 - Estados do domínio da mata Atlântica. Save Brasil, São Paulo, Brasil, 494pp. 
Castiglioni, G. D. A.; Cunha, L. S. T.; Gonzaga, L. P. 1995. Ramphocelus bresilius como dispersor das sementes das plantas da restinga de Barra de Maricá, Estado do Rio de Janeiro. Ararajuba, 3: 94-99.

Cestari, C. 2006. A importância de terrenos com vegetação nativa para aves em áreas urbanizadas no litoral sul de São Paulo. Atualidades Ornitológicas, 5: 14-17.

Farias, G. B.; Alves, A. G. C. 2007. Aspectos conceituais e históricos da etnoornitologia. Biotemas, 20: 91-100.

Howe, H. F. 1981. Dispersal of a neotropical nutmeg (Virola sebifera) by birds. Auk, 98: 88-98.

Naka, L. N.; Rodrigues, M.; Roos, A. L.; Azevedo, M. A. G. 2002. Bird conservation on Santa Catarina island, southern Brazil. Bird Conservation International, 12: 123-150.

Oliveira, M. M. A. 1987. Aves e vegetação em um bairro residencial da cidade de São Paulo (São Paulo, Brasil). Revista Brasileira de Zoologia, 12: 81-92.

Oliveira, M. M. A. 1999. Frugivoria por aves em um fragmento de floresta de restinga no estado do Espírito Santo, Brasil. Tese de Doutorado da Universidade Estadual de Campinas, Brasil, $153 \mathrm{pp}$.
Pizo, M. A. 1997. Seed dispersal and predation in two population of Cabralea canjeriana (Meliaceae) in the Atlantic forest of southeastern Brazil. Journal of Tropical Ecology, 13: 559-578.

Prefeitura Municipal de Itanhaém, 2005. Estatísticas: Demografia. Disponível em <http://www.itanhaem.sp.gov.br/servicos/ estatiscas>. Acesso em 10 de abril de 2008.

Sampaio, D. 2005. Restinga. In: Sampaio, D.; Souza, V. C.; Oliveira, A. A.; Paula-Souza, J. E.; Rodrigues, R. R. (Eds). Árvores da restinga: Guia de identificação. Neotrópica, São Paulo, Brasil, p.25-30.

Sick, H. 1997. A ornitologia brasileira. Nova Fronteira, Rio de Janeiro, Brasil, 862pp.

Souza, V. C.; Capellari Jr., L. 2004. A vegetação das dunas e restingas da Estação Ecológica Juréia-Itatins In: Marques, O. A. V.; Duleba, W. (Eds). Estação Ecológica Juréia-Itatins: Ambiente físico, flora e fauna. Holos, Ribeirão Preto, p.103-114.

Staggemeier, V. G.; Galetti, M. 2007. Impacto humano afeta negativamente e dispersão de sementes de frutos ornitocóricos: Uma perspectiva global. Ararajuba, 15: 281-287.

Terborgh, J. 1986. Keystone plant resource in the tropical forests. In: Soulé, M. E. (Ed.). Conservation biology: The science of scarcity and diversity. Sinauer, Massachusetts, USA, p.330-344. 